\title{
Review: Adaptation of ruminant livestock production systems to climate changes
}

\author{
B. K. Henry ${ }^{1 \dagger}$, R. J. Eckard ${ }^{2}$ and K. A. Beauchemin ${ }^{3}$ \\ ${ }^{1}$ Science and Engineering Faculty, Queensland University of Technology, Brisbane, QLD 4001 Australia; ${ }^{2}$ Faculty of Veterinary and Agricultural Sciences, \\ The University of Melbourne, Melbourne, VIC 3010, Australia; ${ }^{3}$ Lethbridge Research and Development Centre, Agriculture and Agri-Food Canada, 5403 1st Avenue \\ South, Lethbridge, Alberta, Canada
}

(Received 8 December 2017; Accepted 3 May 2018; First published online 24 August 2018)

\begin{abstract}
There is growing evidence on the extent to which projected changes in climate, including increases in atmospheric levels of carbon dioxide, higher temperatures, changes in amount, seasonality and variability of precipitation and increases in extreme weather events, may affect future availability of ruminant animal products. Elements of climate change affect livestock systems through direct impacts on animal physiology, behaviour, production and welfare and indirectly through feed availability, composition and quality. These impacts may be positive or negative and will vary across geographical regions, animal species and with adaptive capacity. However, adverse impacts are likely to be greatest in tropical and sub-tropical regions including countries where both current need and future growth in demand for nutrition is greatest. The complexity of effects means that effective adaptation strategies to mitigate negative impacts on ruminant production systems to climate changes will need to be multi-dimensional. Although predictions of future climate, particularly on regional and local scales, have a degree of uncertainty, adaptation planning is starting to be informed by changes already being observed and adjustments in management being made by farmers to maintain productivity and profitability. Regional case studies illustrate the benefits and limitations of adaptive management: potential mitigation through heightened awareness of heat stress-related mortality in French cattle; evidence of a drop in milk production in south-eastern Australian dairies during a January 2014 heat wave, from the theoretical potential of 53\% to only 10\% across the state; and limitations in response options to climate-induced thermal, nutritional and water stress for sheep and goat farmers in northern Ethiopia. Review of research on climate change impacts on ruminant livestock and effective adaptation together with evidence of practical adaptive management provide insights into potential strategies and gaps in knowledge to address challenges and improve future decisions.
\end{abstract}

Keywords: adaptive management, feed quality, heat stress, cattle, sheep

\section{Implications}

Changes in climate will affect future availability of meat, milk, fibre and other products from ruminant animals. The impacts of higher temperatures, changes in precipitation and extreme weather events will vary across geographical regions, animal species and socio-economic capacity for adaptation. This review examines the evidence for adaptation needs in intensive and extensive cattle, sheep and goat production systems, the growing evidence that responsive management options can mitigate adverse climate change impacts on forage quantity and quality and on animals, and gaps in the knowledge needed for planning more effective short- and long-term strategies.

${ }^{\dagger}$ E-mail: beverley.henry@qut.edu.au

\section{Introduction}

The climate of the Earth is changing. Global average annual temperature has risen by $0.94^{\circ} \mathrm{C}$ above the 20th century average, with the rate of warming very likely unprecedented in over 10,000 years (National Oceanic and Atmospheric Administration, 2017). Observed changes in rainfall intensity (King et al., 2017) and patterns of rainfall change (Stagge et al., 2017) have been linked to global warming. Recent research is revealing not only the spatial patterns likely to develop in future but that these patterns are already evident and measureable (King et al., 2017), providing a strong basis for analysing impacts across regions and evaluating early adaptive responses as well as longer-term options.

The impacts of these changes on agricultural systems such as livestock production will depend not only on specific changes in climate variables, which vary regionally (Stagge et al., 2017), 
but on location-specific conditions including baseline climate and economic vulnerability. The effects on livestock will vary by region, animal species and production type and may be positive or negative (Sejian et al., 2017). For example, northern Europe is already showing signs of being warmer and wetter (Stagge et al., 2017) raising prospects for favourable trends in crop and pasture growth and projected climate changes are expected to positively influence the yield of forage per hectare in Central Europe (Gauly et al., 2013). Other regions such as southern Australia (Howden et al., 2008) and southern South Africa that rely on winter rainfall expect a decline in production.

Future vulnerability also depends on the sensitivity of production to regional climate. Observations that the milk production of Holstein-Jersey dairy cattle in tropical and subtropical conditions may be $40 \%$ to $60 \%$ lower than in temperate conditions (Usman et al., 2013), raises serious concerns about resilience to future global warming. This example highlights the need to understand the role of strategies such as breeding livestock for adaptability rather than exclusively focussing on high productivity especially in the tropics. The best adaptation options will combine technological, behavioural, management and policy options to effectively offset the negative effects of climate changes and maximise any benefits. In some cases, such strategies may also result in improved enterprise profitability through efficiency gains, while in others there may be a lowering of the average short-term returns.

There are many dimensions to adaptation of ruminant livestock production to climate changes (hereafter 'livestock' refers to ruminant species unless otherwise stated). This review examines available evidence on the extent and effectiveness of responses to trends in climate elements such as temperature and to extreme events that are outside the historical experience. We focus on management practices in ruminant production enterprises, particularly cattle and sheep where there are better records and more research while referring to emerging evidence across species and regions. Using case studies, we explore evidence for existing management responses. In conjunction with published research findings, management responses being made now by ruminant livestock farmers provide some insights into the potential for practical and strategic adaptation to projected future changes in climate.

\section{Climate changes and livestock production}

\section{Overview of climate changes affecting livestock production systems}

The impact of climate changes on livestock production will depend on the magnitude and nature of the changes and can be mediated through both direct effects on the animal and indirect effects on their environment; for example, through feed quantity and quality.

Changes in climate variables are commonly expressed relative to a 1960-90 'climate normal' baseline; for example, temperature increases of $1.5^{\circ} \mathrm{C}$ or $2.0^{\circ} \mathrm{C}$ above this baseline correspond to agreed efforts to limit global warming by 2100 under the Paris Agreement of December 2015 (United Nations Framework Convention on Climate Change, 2015). The impacts of climate changes with $2^{\circ} \mathrm{C}$ average global temperature rise may be more severe than assessed in earlier studies by the Intergovernmental Panel on Climate Change and may be felt sooner. In particular, the risks associated with increasing frequency and severity of extreme weather events (Tebaldi and Wehner, 2018) appear to be significantly greater at a global average increase of $2^{\circ} \mathrm{C}$ than at $1.5^{\circ} \mathrm{C}$.

For agriculture, prospects of changes in regional patterns of rainfall as well as temperature are important for developing adaptation strategies. Global precipitation changes and the overall intensification of the hydrological cycle respond to factors other than rising temperature; for example, local soil moisture feedback mechanisms. This results in a higher degree of uncertainty for livestock production.

\section{Regional climate change impacts}

Modelling predicts significant differences in regional climate indicators (King and Karoly, 2017; King et al., 2017) not only in the severity but also the direction of changes. Results indicate that tropical and subtropical regions will face negative impacts earliest and, in fact, climate changes are already being observed in some areas, for example, Australia (King et al., 2017) and south-east Asia (Thirumalai et al., 2017).

The tropics and subtropics are home to much of the world's grasslands and grazing lands and to some of the world's poorest peoples who rely on those lands for food security. Ruminant livestock is critical to meeting nutritional needs in these regions where socio-economic factors, including a reliance on local food production and vulnerability to land degradation, add to the risk of food insecurity. While communities have traditionally managed for high climate variability using locally adapted breeds of animals that are more resilient than many temperate phenotypes, the capacity to cope with hotter, often drier and more extreme conditions in the future will require additional investment in adaptation.

Understanding the impacts of climate changes is critical to developing effective adaptation strategies. First, the perceived risk is a major determinant of investment in adaptive actions, and second, the effectiveness of adaptation strategies depends on how well they are matched to the impacts. In livestock production systems there is evidence of incremental changes in management occurring in response to trends in climate averages. Transformative adaptive responses will more likely be driven by extreme conditions that occur less regularly and threaten the survival of animals and those who depend on them. It is the extreme conditions that determine viability, profit and animal productivity and welfare outcomes as recorded in recent events such as the record hot summer of 2003 in Europe, which also caused tens of thousands of human deaths (King and Karoly, 2017).

Despite remaining uncertainties in simulations of the impacts of global warming, research is guiding decisions by farmers, industry and policymakers. Regional analyses for 
Australia and Europe on the effects of different levels of warming on large-scale heat extremes (King and Karoly, 2017; King et al., 2017) demonstrate the need for change. For example, under $2^{\circ} \mathrm{C}$ global warming, large scale heat waves such as that experienced in Europe in the summer of 2003 may occur as often as one in every 2 years. In Australia, the very hot summer experienced in 2012-13 is predicted to be more common under either $1.5^{\circ} \mathrm{C}$ or $2^{\circ} \mathrm{C}$ warming. While not precise, these studies highlight the risk of business-asusual management, and particularly in industries such as ruminant livestock production that are both sensitive to climate impacts and generally located in regions more vulnerable to extreme changes resulting from global warming. A significant gap in knowledge relates to hydro-meteorological extremes that are of high importance for livestock production particularly in arid and semi-arid regions.

\section{Ruminant production and climate vulnerability}

Livestock, including ruminant and monogastric species, contribute $18 \%$ of global kilocalorie consumption and $25 \%$ of global protein consumption (Mottet et al., 2017). Globally, ruminants (cattle, buffalo, sheep and goats) produce an estimated $36355 \mathrm{Mt}$ of protein per year (Mottet et al., 2017) and provide micronutrients essential for human well-being. The ability of ruminants to convert ligno-cellulose to meat and milk that are sources of high-quality protein and essential nutrients contributes significantly to human health. This is particularly important in some of the poorest regions of the world. In addition, ruminant livestock make a positive contribution to food security and well-being of communities by providing manure and draught power for other agricultural production. Livestock is also a reliable source of income from household to national scales. Maintenance or growth of the sector to meet future demand for products and services provided by ruminant livestock must be balanced against a need to manage the well-documented environmental impacts and potential for negative consequences for global food security. These include significant contributions to greenhouse gas emissions, water use and occupation of land suitable for human food production for grazing or feed production (Opio et al., 2011; Henry et al., 2012; Mottet et al., 2017).

Global food security and the growing demand for animal products related to rising population and increasing income emphasise the importance of climate adaptation strategies to minimise adverse impacts on animal production. However, ruminant agriculture is arguably one of the food and fibre production systems most vulnerable to climate changes. Much of the production is in extensive rangelands where inputs are low, and forage production and water supply vary with seasonal climate. Global feed production for all livestock requires 2.5 billion ha of land, but $\sim 90 \%$ of livestock protein is derived from feed produced on 2 billion ha of grassland of which 1.3 billion ha is non-arable (Mottet et al., 2017). Much of the rangelands occupied by ruminant animals is in tropical and subtropical regions sensitive to the impacts of climate changes, with more than $50 \%$ of total meat and $60 \%$ of milk produced in these zones (Mottet et al., 2017). Intensive ruminant production is more vulnerable to welfare and health impacts of climate changes through heat stress and there is a threat to both intensive and extensive systems of new or expanded exposure to pests and disease.

Potential impacts of climate changes on livestock include direct effects on animal physiology, production and behaviour (Henry et al., 2012) and indirect effects mediated by changes in water availability and the quantity and quality of forage and feed crops (Craine et al., 2016). Factors influencing these effects include increases in atmospheric levels of carbon dioxide $\left(\mathrm{CO}_{2}\right)$, higher temperatures and changes in amount, seasonality and variability of precipitation (Henry et al., 2012). Changes are already being observed by farmers in some regions. For example, in northern Australian rangelands, projections of longer, more severe droughts will increase the risk of land degradation, while heavier rainfall and flooding events are likely to also contribute to extensive soil erosion and to expanding the range of some weeds, pests and diseases (McKeon et al., 2009).

Changes by farmers already being initiated in response to effects in pasture systems include adjusting inputs (e.g. fertilizer or irrigation), selection of forage species (including deep-rooted grassland mixtures in drought and water-logged soils; Hoekstra et al., 2015), managing grazing times and rotations, and farm system choices such as cropping/pasture mix (Cullen et al., 2012). Responses to direct impacts on ruminant animals include changes in feed management (e.g. balancing feed, forage, supplements), stocking rates, genetic selection, disease risk management (e.g. vaccination or selection of resistant genotypes), climate control (e.g. shade, fans, water sprays) and timing of reproduction.

\section{Adaptive response of livestock production to indirect impacts}

\section{Climate changes and forage production}

Climate change effects on productivity and quality of pasture and forages consumed by ruminants are expected to be regionally specific. In temperate regions, the effects of climate changes on grassland production may be positive due to prolonged growth with slight increases in ambient air temperature combined with elevated $\mathrm{CO}_{2}$, provided water and nutrient supplies are not limiting. In tropical and subtropical rangelands, however, both high temperatures and water scarcity appear more likely to result in lower forage quantity under future climate. In both regions, nutritive value of forages may decrease as crude protein (CP) and digestibility decline. More research is needed to understand the species mix most likely to support livestock ranging from high producing dairy cattle to hardy beef cattle, sheep and goats.

With a changing climate, there is potential for changes in both the between-year variability and the within-year seasonality of production. Climate changes are likely to mean more severe drought conditions, through greater evapotranspiration (Hennessy et al., 2010) which will exacerbate plant water stress, and increased intensity of large-scale 
climate drivers (e.g. El Niño and Indian Ocean Dipole). These impacts in turn will result in greater variability in forage production between years, with adaptation options focusing on improving longer-range weather forecasting, coupled with more proactive risk management (e.g. increased forage conservation or resting pasture).

\section{Changes in pasture species}

In regions where rainfall is evenly distributed or summerdominant and future scenarios predict that this pattern will continue with warming, then it is likely that $C_{4}$ grasses could dominate production in future climates (Howden et al., 2008; Cullen et al., 2012). Typically, this could occur in regions intermediate between winter and summer dominant rainfall, as climate change warms the mid-latitudes and pushes weather systems poleward. Proactive adaptation in these regions would seek to capitalise on the change through a mixture of $C_{3}$ and $C_{4}$ species in forage systems, thereby spreading risk and capturing the best of both warm and cooler season rainfall (Cullen et al., 2012).

In Mediterranean climates or winter-dominant rainfall regions, where future climate predictions show no shift in rainfall distribution, the productivity of summer dominant forages and pastures will only improve at the shoulders of the production season. Under these conditions, studies show very limited benefit of a shift from $C_{3}$ to $C_{4}$ species, with adaptation focusing more on selection of heat tolerance and deeper rooting $C_{3}$ species (Cullen et al., 2012).

\section{Changes in forage quality}

A changing climate is likely to affect forage quality in ways that vary regionally. For example, a meta-analysis by Dumont et al. (2015) reported differences in the expected effects in mountain regions, which may benefit from a change in climate through warmer winters reducing low-temperature limitations to pasture growth, as compared with Mediterranean regions where drought and heat may constrain pasture quality in future climates. In species that require vernalisation for flowering quality decline may be associated with both earlier flowering and reduced seed production. Craine et al. (2017) reported that increasing temperature and declining precipitation decreased forage $\mathrm{CP}$ content and increased the ratio of digestible organic matter to CP content for regions with continental climates. The cost of providing supplemental CP (e.g. soybean meal) to US cattle to compensate for the decline in CP content of forage was estimated at $\$ 1.9$ billion USD annually (Craine et al., 2017). Additionally, increasing use of human-edible feed and soybean meal, currently estimated at $6.7 \mathrm{~kg} / \mathrm{kg}$ protein produced from ruminant livestock (Mottet et al., 2017) may contribute to environmental costs with soy production considered a major driver of land-use change. In temperate high rainfall climates, particularly in dairy pastures where nitrogen $(\mathrm{N})$ fertiliser is applied, pasture protein levels are typically in excess of animal requirements for much of the year. Hence a reduction in plant $\mathrm{CP}$ content may well be beneficial to livestock production while also reducing urinary $\mathrm{N}$ loss and thus nitrate leaching and nitrous oxide and ammonia emissions to the atmosphere (Wilkinson and Lee, 2017). However, in more extensive grasslands already marginal in CP content, it is both impractical and ineffective to apply $\mathrm{N}$ to redress this protein deficit. Adaptation strategies are likely to require more $\mathrm{CP}$ supplementation in these more extensive grazing systems in future climates. In addition to limiting animal growth, a decline in forage quality may also promote greater enteric methane production. High fibre, low digestibility feeds favour biochemical pathways that form more hydrogen and slower rumen passage, both of which raise the potential for methane loss (Wilkinson and Lee, 2017).

In summary, there is a need for greater research on the effects of individual and combined climate change factors (elevated temperature and $\mathrm{CO}_{2}$ levels, drought) on forage production and quality as the interactions among these factors make it exceedingly difficult to predict responses.

\section{Changes in rangeland composition}

While climate change is likely to affect the mix of herbaceous species in a grassland system, there is also evidence that rising $\mathrm{CO}_{2}$ levels and increasing temperatures may be driving an underlying change in the balance between herbaceous and woody species in grasslands. A recent analysis of growing season integrated Leaf Area Index shows increased greening in over $25 \%$ to $50 \%$ of the global vegetated area (Zhu et al., 2016), with multiple global ecosystem models suggesting that $\mathrm{CO}_{2}$ fertilisation explains $70 \%$ of the observed greening trend. Similarly, modelling of the Australian rangelands showed a significant shift in areas of vegetation classes from the period of 1931-70 to 1971-2010 due to the increased rainfall over large areas (Liu et al., 2017). This modelling projected a range of changes in vegetation classes for 2050 depending on the climate change scenario used, with Net Primary Productivity likely to increase in Australian rangelands depending on management of cattle and sheep grazing. In the grazed savannas, use of fire and other management strategies to control proliferation of woody vegetation will affect the balance between net carbon accumulation in vegetation and soil, relative to livestock and savannah burning emissions, and thus whether these regions are a net carbon sink or source (Burrows et al., 2002).

Rising atmospheric $\mathrm{CO}_{2}$ has been shown to be a key explanatory driver for observed bush encroachment (Scheiter and Higgins, 2009) in sub-Saharan Africa. Further analysis shows that $\mathrm{CO}_{2}$ fertilisation is not saturated at current ambient levels and would increase in response to increasing $\mathrm{CO}_{2}$ levels. Together with evidence that rising $\mathrm{CO}_{2}$ levels are reducing the $\mathrm{CP}$ content of unfertilised native grasslands (Craine et al., 2017), the savannah grasslands of the world will very likely continue to be challenged by bush encroachment into the foreseeable future. With increasing public resistance to expansion of land clearing for livestock production, the active management of bush encroachment could become a contentious issue for livestock industries in future. One adaptation option would be to develop a broader carbon 
offset market for farmers to be rewarded for avoided deforestation and management of native forest regrowth, combined with practices to more efficiently manage whole farm productivity and potentially growth in intensive pasture or feedlot feeding to maintain or increase total output.

\section{Genetic diversity of plants}

Models have been used to predict the response of plant traits to selection under climate change (Hoffmann and Sgrò, 2011). These models predict that extinction rather than evolution is likely if environmental conditions change too quickly. However, climate change can also increase the intensity of directional selection for particular traits, theoretically leading to a faster evolutionary response (Hoffmann and Sgrò, 2011). It is unclear whether individual forage species can evolve to keep up with the rate of climate change, or if outcomes are more likely through changes in species composition across multi-species grasslands.

Climate change adaptation involves increasing the resilience of the system, on the assumption that future climates will push species to the limits of their tolerance range. This can be achieved through both increasing within and between species diversity in the forage or pasture system. Intensive selection of forage species over multiple generations has resulted in highly productive pastures and the forages species in use today. Improved pasture species such as perennial ryegrass (Lolium perenne), have historically been selected for increased winter production, perhaps at the expense of drought and heat tolerance, and such species may have less genetic diversity than their ancestral parent populations. This makes them more vulnerable to a change in their ideal growing environment; particularly as they are typically sown in mono-specific swards. Cullen et al. (2012) showed that annual pasture production of a range of $C_{3}$ species either increased or showed little change with up to $2^{\circ} \mathrm{C}$ warming in south-eastern Australia, but production declined rapidly thereafter, and more heat-tolerant $C_{4}$ grasses were required to maintain forage production. In contrast, with the natural distribution of the $C_{4}$ grass, Themeda triandra, extending throughout Australia, southern and eastern Africa, Southeast Asia, India and the Middle East (Snyman et al., 2013), this species is likely to have a significantly greater inherent genetic diversity to adapt to a changing climate, albeit with lower productivity than pastures like perennial ryegrass. In Europe, cultivars of Festulolium (Fescue $\times$ Lolium hybrids) are being studied for a potential role in adaptation of pastures to climate change through improved growth in winter waterlogged soils or in warmer, drier summers as extreme conditions increase. Overcoming low productivity relative to ryegrass will limit widespread use for some time, but some use to increase diversity and, hence, resilience to climate may occur (Ghesquière et al., 2010).

In contrast to mono-specific pastures, species-rich grasslands should have greater between-species diversity to help maintain ecosystem function with changes in climate. Craine et al. (2013) show that most native grasslands contain a high diversity for drought tolerance, concluding that these diverse grasslands throughout the globe have the potential to be resilient to drought in the face of climate changes through local expansion of drought-tolerant species.

Climate change adaptation may therefore require land managers to limit mono-specific forage and pasture systems to regions with low rainfall variability and where temperature changes remain within the thermal tolerance of the selected species. In regions of higher rainfall variability and greater temperature change, a multi-species grassland system is likely to confer greater resilience as the climate changes, but also allowing natural selection to drive the species composition change.

\section{Adapting to changing water security}

Water is a crucial factor in agricultural food production. Projected decreases in reliability of rainfall including drier conditions in tropical and sub-tropical regions (Hennessy et al., 2010) will affect feed availability for both grass-fed ruminants and those receiving supplementary grain feed. Maintaining production with less reliable precipitation will likely mean a greater reliance on irrigation. The FAO has estimated that the livestock sector uses about $35 \%$ of total cropland and about $20 \%$ of blue water for feed production (Opio et al., 2011), with the proportion used for ruminant production varying seasonally.

Water intake by livestock is related to animal size, age, diet (e.g. moisture content), animal activity, temperature and physiological status of animals (e.g. lactation and growth rate). Higgins et al. (2008) recommended drinking water for cattle should be between $5^{\circ} \mathrm{C}$ and $18^{\circ} \mathrm{C}$ and noted that when the ambient temperature exceeded $27^{\circ} \mathrm{C}$, water and feed intake decreased negatively affecting animal productivity. It has been estimated that cattle will require $13 \%$ more water for a temperature increase of $2.7^{\circ} \mathrm{C}$ in a sub-tropical region (Harle et al., 2007).

In response to global warming, adaptation strategies will be needed to meet freshwater requirements, in terms of both quantity and temperature, for both productivity and welfare of ruminants. Adaptation strategies for changes in water availability and water needs may include both infrastructure and management options. Projected precipitation and evapotranspiration rates support forward planning for increased investment in storage tanks and dams. New dams and catchments need to be designed to better cope with future demand and for less evaporative loss. In rangelands increasing the number of watering points will reduce the distance animals have to walk to drink and will have the co-benefit of encouraging more even pasture utilisation. In these extensive systems, including shade over watering points will reduce evaporative loss, reduce water temperatures, increase the efficacy of water intake by animals and thus assist with reducing heat stress (Gaughan et al., 2010a). In intensive production such as dairy or feedlot cattle systems increasing effluent and water re-use for wash-down and irrigation will improve resource efficiency and assist adaptation. 
Henry, Eckard and Beauchemin

\section{Adaptive response of ruminant production to heat stress}

\section{Heat stress}

Acute heat stress can lead to morbidity in livestock and the management of long-term high ambient temperatures or short-term acute heat waves is a critical concern for animal welfare as well as for food and fibre production. However, chronic heat stress may lead to greater economic loss through sub-clinical health issues and overall reduced animal performance. Livestock normally maintain their body temperature within a fairly narrow range $\left( \pm 0.5^{\circ} \mathrm{C}\right)$. When animals are exposed to combinations of high temperature, solar radiation and humidity and are not able to adequately dissipate accumulated heat, heat stress occurs (Das et al., 2016; Seijan et al., 2017).

A heat stress response can be influenced by numerous factors: species, breed, previous exposure, health status, level of performance, body condition, age, coat colour, lactation stage and body condition (Dunshea et al., 2013; Das et al., 2016). The negative effects of heat stress include compromised metabolic and digestive functions (Gauly et al., 2013) that reduce milk production and quality, compromise animal welfare, reduce reproductive efficiency, and in extreme cases, cause death (Kadzere et al., 2002; Das et al., 2016).

The intensity and duration of exposure to hot and humid conditions is also a factor in heat stress (Dunshea et al., 2013). Whilst there is extensive research into the impact of short-term acute heat stress on dairy cattle (Kadzere et al., 2002; Garner et al., 2017), research into extended exposure to heat stress and its cumulative effects under farm conditions is limited with the exception of beef feedlot studies (e.g. Gaughan et al., 2010a). Under conditions of acute heat stress, milk productivity has been shown to be negatively affected within $24 \mathrm{~h}$ in proportion to heat load (Silanikove et al., 2009). Garner et al. (2017) found that exposing dairy cows to moderate heat stress over 4 days in a climatechamber controlled study reduced milk yield by $53 \%$ and reduced dry matter intake by $48 \%(n=6)$. Heat stress events may be mitigated by cooler night-time temperatures that allow the cow to offload accumulated heat (Silanikove et al., 2009; Dunshea et al., 2013).

\footnotetext{
Management options

The impacts of extreme heat load events on livestock can be mitigated by adjusting their environment and diet, and by selecting animals that are more heat tolerant (Renaudeau et al., 2012). Adjusting the animals' environment and improving the ability of the animal to dissipate body heat can include providing shade, sprinklers, misters and fans, but ensuring access to adequate drinking water is paramount (Gaughan et al., 2010a; Henry et al., 2012). Nutrient deficiencies arising from heat stress can be mitigated by adjusting diets. For example, increasing $C P$ and digestible energy content of diets can help compensate for lower feed intake during heat stress while decreasing fibre content of
}

diets decreases metabolic heat production (Das et al., 2016). Supplementation with vitamins $C, E$ and $A$, certain trace minerals (e.g. zinc, selenium) and electrolytes may help relieve oxidative stress and boost immunity (Das et al., 2016), although more research is needed to understand the unique challenges of meeting the nutrient requirements of heat-stressed ruminants.

Gantner et al. (2017) found that some animals within the same breed exhibit greater tolerance to heat stress due to genotypic differences. With the progression of climate change longer-term, however, livestock producers in more marginal regions may need to consider changing the types of animals and genotypes used (Gaughan et al., 2009).

\section{Beef cattle}

Pastured beef cattle are usually able to seek shade, water and air movement to cool themselves, thus heat stress is usually a greater problem for feedlot cattle than breeding cows and growing cattle in rangeland or pasture settings. However, heat stress can negatively affect reproductive function of beef cows. For example, cows exposed to elevated ambient temperature during late gestation experienced premature onset of parturition due to increased body temperature (Wright et al., 2014). In feedlots, animals experience radiant heat from dirt or concrete surfaces and without appropriate management will show performance loss due to decreased efficiency and feed intake resulting from physiological stress (Mader et al., 2006). Inability to abate the greater heat load can potentially result in death. Management strategies to reduce the risks in feedlots may include regular removal of manure, diet changes to reduce digestive metabolic heat (e.g. increased fat content, lower fibre content), frequent water changes to ensure availability of cool, clean water and provision of additional shade and cooling (e.g. sprinkler) equipment. Warning systems using heat load triggers such as prolonged high temperature and humidity, or forecasted extreme weather are already being used to activate management response in feedlot conditions (Mader et al., 2006; Gaughan et al., 2010a; Henry et al., 2012).

\section{Dairy cattle}

Dairy cattle are highly susceptible to heat stress, more so than other cattle breeds due to their relatively higher metabolic rate during lactation (Das et al., 2016). Heat stress reduces milk yield, milk components, fertility and feed efficiency, while increasing culling and mortality rates (Das et al., 2016). Furthermore, the effects of heat stress increase with parity of dairy cows (Misztal, 2017). An analysis of the US dairy industry projected a $0.60 \%$ to $1.35 \%$ decline in milk production by 2030 due to heat stress, depending upon the climate model used (Key and Sneeringer, 2014). In southern States, losses greater than $2 \%$ were predicted.

Dairy animals are able to acclimate to their environment to some extent. Higher producing dairy breeds originating from temperate climates (e.g. Holsteins) have been shown to be less able to cope with heat stress than lower producing 
breeds from warm and humid climates (e.g. Jerseys) (Nidumolu et al., 2010). This is further compounded by higher producing cows having a greater susceptibility to heat stress, as metabolic heat increases with feed intake required to maintain higher production levels (Dunshea et al., 2013).

Management strategies to reduce the impact of heat stress on dairy cattle would be similar to those of feedlot cattle, addressed above.

\section{Sheep}

Sheep and goats appear generally less susceptible to heat stress than other domesticated ruminants, with unique characteristics such as water conservation capability, higher sweating and respiratory rate and lower basal heat production (Kadzere et al., 2002). However, heat stress especially when accompanied by high ambient humidity has been shown to be a major factor in poor reproductive performance of sheep in pastoral environments (Harle et al., 2007). When exposed to continuously hot conditions, ewes that are poorly adapted to heat stress may suffer increased levels of embryonic mortality and reduced foetal growth, and mortality in lambs from heat-stressed ewes appears to be higher than in lambs produced during cooler conditions (Harle et al., 2007). However, ewes acclimatised to high temperatures and subjected to diurnally fluctuating temperatures do not show these effects indicating potential for adaptation to hotter conditions (McCrabb et al., 1993).

Under future levels of global warming, the combination of lower reproductive rates, poorer growth and survival of lambs and reduced growth of adult sheep may make some areas less suitable for sheep production under climate change. Gaughan (2017) suggests that indirect effects of climate change, for example, on nutrition, may be more important for future sheep production than direct impacts of higher temperatures. However, there is evidence for benefits from adaptive management strategies including stronger selection for more heat tolerant animals, preferential supplementary feeding of ewes, ultrasonic scanning of ewes during pregnancy to target beneficial management, and, where appropriate, shifting mating time so that lambing coincides with peak forage availability and more moderate temperatures.

\section{Goats}

Goats are renowned amongst ruminants for their ability to tolerate extremes of temperature and humidity and to function well even in conditions of water deprivation, water restriction and energy restriction (Kaliber et al., 2016). An ability to reduce metabolism allows goats to survive even after prolonged periods of severe limited food availability. In a Turkish study on crossbred goats (a mix of 75\% temperate breed with $25 \%$ locally adapted breed), the animals showed capacity to endure significant and extended water restriction (Silanikove, 2000). During summer (July-August), with average daily temperature of $34.2^{\circ} \mathrm{C}$ (ranging from $23.1^{\circ} \mathrm{C}$ to $42^{\circ} \mathrm{C}$ ) and an average relative humidity of $68.2 \%$, goats demonstrated a capacity to endure significant water restriction for $>30$ days, with minimal disruption of plasma electrolyte and metabolite composition, thermoregulation and general well-being (Kaliber et al., 2016).

Adaptive responses to future climate changes may include monitoring for indications of heat stress, increased disease monitoring and increasing access to clean water and feed where coping thresholds are exceeded.

\section{Animal genetic strategies}

Species selection in response to climate change

Seo et al. (2010) reviewed the scientific evidence for effects of climate conditions on livestock production. Indicators of animal performance such as weight gain, milk production, wool production and reproductive efficiency were influenced by ambient temperature, humidity and wind speed.

The impacts of climate change in more marginal climatic regions and the sensitivity of animal husbandry to climate may lead to an adjustment of livestock species to maintain the viability of farm enterprises (e.g. Seo and Mendelsohn, 2008; Seo et al., 2010). Modelling by Seo et al. (2010) indicated that in South America, adaptation responses to climate change in terms of species selection varied with climate scenario and between countries. Under a hot and dry future scenario, numbers of beef and dairy cattle would decrease by $3.2 \%$ and $2.3 \%$, respectively, while sheep numbers would increase by $7 \%$. An increase in the sheep population was predicted to occur mainly in the Andes mountain countries of Chile, Colombia, Ecuador and Venezuela. For a milder and wetter climate scenario beef cattle increased in countries of high current production, such as Argentina and Chile. Using data from 9000 African livestock farmers in 10 African countries, Seo and Mendelsohn (2008) reported that farmers were more likely to maintain livestock as temperatures increased and as precipitation decreased, whereas under cooler temperatures and wetter conditions, they favoured crop production. In warmer locations, producers favoured goats and sheep rather than beef cattle and chickens. Thus, farmers may adapt to climate change by shifting from crop production towards livestock production, or mixed farming systems, with a shift in the animal species most suited to the local environmental conditions.

\section{Breed selection: climate tolerance v. performance}

Selection of high-performance animals over many years has clearly led to increased productivity in cattle and sheep. However, genetic selection is usually carried out under optimal temperature and humidity conditions and is frequently tailored to more intensive systems in temperate climates or controlled, air-conditioned housing. This approach may result in animals that are less adaptive to less favourable conditions (e.g. Eisler et al., 2014; Misztal, 2017). There is a strong relationship between production level and metabolic heat generation (Renaudeau et al., 2012) so that selection for improved meat, milk and/or fibre traits may increase animal susceptibility to elevated temperatures. An indication of the potential vulnerability to global warming of high-performance 
stock can be seen in poor outcomes such as when Holstein dairy cows bred in Europe were imported into hot regions of Sub-Saharan Africa or India (Eisler et al., 2014). Experience in the Indian state of Kerala has shown that smaller native cows are economically favoured over imported large bodied breeds despite having less than one-third the milk yield as health and survival requires less inputs (Eisler et al., 2014). Many local breeds of cattle in these tropical latitudes have lower basal metabolic rates and can dissipate a substantial amount of heat by sweating and panting, and thus are more resilient under heat stress (Gaughan et al., 2010b).

Natural selection has favoured breeds with higher heat tolerance that are more able to cope with thermal variations and stress in tropical and sub-tropical regions. These tropically adapted breeds also have a greater capacity to grow and reproduce during unfavourable seasonal conditions with poor nutrition and higher disease and parasite pressures than high-performance breeds (Renaudeau et al., 2012). Eisler et al. (2014) warn of the unsustainability of replacing locallyadapted animals with those selected for optimal conditions in temperate climates. Nevertheless, despite a high level of selection in some species of domesticated livestock, there is still significant genetic variation for many traits that could provide potential for further adaptation (Hayes et al., 2013).

Genomic selection that enables prediction of the genetic merit of animals from genome-wide single nucleotide polymorphism markers is expected to continue to be adopted to increase genetic gains in growth rates, milk production and other desirable traits (Hayes et al., 2013). Alongside more traditional selection and cross-breeding methods the use of whole-genome sequence data and advanced reproductive technologies can assist in accelerating selection to a level needed for adaptation to expected rates of climate changes. However, genetic selection for lower body temperature as a strategy to reduce the magnitude of heat stress effects in dairy cattle may be limited due to adverse association with economic indicators. Dikmen et al. (2012) found a significant genetic correlation between rectal temperature in Holstein cattle under heat stress conditions and traits important to productivity, including 305-day yields of milk, fat, and protein, productive life and net merit. Conversely, genetic correlations between rectal temperature and somatic cell count score and daughter pregnancy rate were significant and negative.

The divergence between European and African evolved cattle, Bos taurus, and the tropically adapted Bos indicus (zebu) of Indian origin, in terms of genetic traits, provides some insight into the potential for future breeding for climate change adaptation. Among the genetic adaptations in zebu cattle have been the acquisition of genes for heat tolerance. Zebu cattle are better able to regulate body temperature in response to heat stress due to a number of physiological and cellular level traits (Hansen, 2004; Gaughan et al., 2010b) which confer superior ability for regulation of body temperature during heat stress due to a combination of lower metabolic rates and increased capacity for heat loss. Tissue resistance to heat flow from the body core to the skin is lower for zebu cattle, while sweat glands are larger in comparison to European breeds. In addition, the hair coat in zebu cattle enhances conductive and convective heat loss and reduces absorption of solar radiation. At the cellular level, genetic adaptations mean that elevated temperature is less likely to result in preimplantation embryos being inhibited during development for zebu than are embryos from European breeds (Hansen, 2004).

Traditional cross-breeding has been used to introduce the zebu genotype into Bos taurus breeds to develop cattle for beef and dairy production in hot climates. Success has been limited due to co-introduction of other unfavourable genetic characteristics of zebu cattle, particularly those associated with low productivity. In addition, it is now becoming clear that the rate of change in climate is faster than the rate of genetic improvement possible using traditional selection methods (Gaughan et al., 2009; Hayes et al., 2013). It is uncertain whether the most effective approach would be to identify phenotypes in a heat-tolerant breed that have favourable production and market traits or to select heattolerant animals within breeds that meet market specifications (Gaughan et al., 2009). An alternative approach is to incorporate specific thermo-tolerance genes from zebu cattle into European breeds while avoiding undesirable genes. This approach relies on firstly being able to identify and map specific genes responsible for thermo-tolerance in zebu, and then to develop breeding strategies such as marker-assisted selection and transgenics to better utilise the zebu genotype for cattle production systems (Hansen, 2004).

The Senepol breed, and some other tropically adapted breeds of Bos taurus cattle with short smooth hair as well as their crosses with Holstein, Charolais and Angus animals can show similar heat tolerance to Bos indicus cattle. The heat tolerance of cattle with slick hair, a trait controlled by a major dominantacting gene, appears to be mostly associated with coat type although sweating ability may also be enhanced (Olson et al., 2003). Olson et al. (2003) found that slick haired crossbred calves of Carora (a slick-coated breed) and Holstein origin had lower rectal temperature $\left(0.18^{\circ} \mathrm{C}\right.$ to $\left.0.4^{\circ} \mathrm{C}\right)$ than equivalent normal haired animals and these crossbred cows had a production advantage over a full lactation of $810 \mathrm{~kg}$ milk. However, the advantage of the slick hair coat trait has been recently contested (Davis et al., 2017), highlighting the challenges of genetics-based solutions in adaptation to climate change.

\section{Pests and diseases}

There is evidence that the severity and distribution of livestock pests and diseases are climate sensitive (McKeon et al., 2009; Henry et al., 2012). However, the effects of climate change on pests and diseases affecting livestock, specifically, has received limited attention to date. Climate change may affect the host environment, the vector, the pest or disease itself and the epidemiology, all of which need to be studied further (Thornton et al., 2009).

Higher temperatures and changes in rainfall, especially changes in sequences of weather events, may favour some 
pests and diseases, while disadvantaging others, leading to changes in the distribution and abundance of these. Often the pests and vectors of disease require specific climatic conditions to establish populations and, while climate change may increase temperatures generally, rainfall changes are far less certain. The relationship between pathogens, vectors, host and climate is complex and difficult to predict and simple models suggesting a poleward movement of pests and diseases miss this complexity (Kovats et al., 2001). Thus, warming of temperate regions does not necessarily mean that new populations of tropical pests, weeds and diseases will establish in these regions. For example, Thornton et al. (2009) reviewed research indicating that climate change may modify habitat suitability of the tsetse fly and mosquitoes, plus increase the number of people at risk, but land use change is likely to have a much larger impact on future transmission of these diseases. Together with practical challenges such as vaccination and distance in extensive production systems, this suggests that effective adaptation response strategies are difficult to implement and that more integrated and interdisciplinary research is required to understand the likely future impacts of climate change on pests and diseases in livestock. Hence, developing effective strategies to deal with new threats is a high priority for livestock industries adaptation.

\section{Lessons in adaptation: case studies}

\section{Adaptation to acute heat stress in French cattle}

The impact of extreme temperature events on ruminant production systems can be seen in a study by Morignat et al. (2014) that examined cattle mortality related to two severe heat waves in France. In August 2003, the average maximum temperature in France increased from the normal seasonal mean of $25^{\circ} \mathrm{C}$ to $37^{\circ} \mathrm{C}$ where it remained for more than 2 weeks. In 2006, temperature steadily increased from midJune onwards, exceeding $30^{\circ} \mathrm{C}$ during most of July, making it the warmest July since 1950, although temperatures were less extreme than in 2003. Overall, cattle mortality increased by $24 \%$ in 2003 and by $12 \%$ in 2006 (Table 1). In 2003 the mortality occurred during the 2 weeks of the heat wave as well as during the following weeks, whereas in 2006 the

Table 1 Increased cattle mortality (\%) during the 2003 and 2006 heat waves in France (Morignat et al., 2014)

\begin{tabular}{llr}
\hline \hline Animal category & 2003 & 2006 \\
\hline Dairy & & \\
$\quad$ Calves 0 to 7 days & 13 & 6 \\
6 months to 2 years & 17 & 16 \\
2 to 5 years & 31 & 18 \\
Beef & & \\
$\quad$ Calves 0 to 7 days & 10 & 18 \\
6 months to 2 years & 47 & 15 \\
2 to 5 years & 31 & 2 \\
All cattle & 24 & 12 \\
\hline \hline
\end{tabular}

mortality occurred during the $2^{\text {nd }}$ and $3^{\text {rd }}$ week of the heat wave with no carryover effects afterwards. In the severe conditions of 2003, all categories of cattle were affected with no difference in mortality between dairy and beef cattle. In contrast, in 2006 the mortality rate of mature animals was greater for dairy than beef, consistent with expectations that dairy cattle, especially older animals, are less able to cope with heat stress. Increased mortality in 2003 compared with 2006 undoubtedly reflects the greater intensity of the heat wave in 2003, but it may also reflect increased awareness of livestock farmers of the severe consequences of excess heat as a result of having experienced the 2003 heat wave. The study demonstrates the potential negative consequences of climate variability for the cattle industries and the benefits of increased producer awareness of preventative management practices to help mitigate the extreme effects of heat stress.

\section{Adaptation to extreme heat wave conditions in Australian dairy cattle}

Garner et al. (2017) found that cows exposed to moderate heat stress in a controlled environment-chamber had a milk yield reduction of $53 \%$. However, the fact that this level of impact is seldom observed at an industry level illustrates that operational management adjustments by dairy farmers, in response to experienced climate, over time increases their resilience to climate 'shocks'.

Milk tanker pick-up data from dairy farms distributed across the state of Victoria, throughout one of the most extreme heat wave events in Australia's history that occurred from 13 to 18 January 2014, were analysed. The event ranked along with the 2009, 1939 and 1908 heat waves as one of the most significant multi-day heat waves on record and was the hottest 4-day period on record in Victoria, for both maximum and daily mean temperature (Australian Bureau of Meteorology, 2014).

Figure 1 shows the milk tanker pickups from the 640 dairy farms spread across the dairy regions of Victoria, collected every $2^{\text {nd }}$ day, together with the state-wide average maximum and minimum daily temperatures and the calculated Temperature Humidity Index (THI) (Dunshea et al., 2013). Notable in the data is that the THI exceeded 72 , the threshold for onset of mild heat stress, for 5 days. Additionally, nighttime minimum temperatures remained above $21^{\circ} \mathrm{C}$ for three nights in a row. Relative humidity for the days above THI 72 was below $33 \%$, averaging $61 \%$ for the 4 days following the event.

While the heat wave impact is clear in the milk production of these dairy cows, the average drop in milk production across the state was only $10 \%$ below the average 14-day running mean for the 5 days before the event. Compared with the $53 \%$ potential reduction reported by Garner et al. (2017) for cows in chambers $(50 \%$ to $60 \%$ relative humidity and constant wind speed of $7.8 \mathrm{~m}^{3} / \mathrm{min}$ ), the much lower drop in milk production could demonstrate the potential efficacy of on-farm management intervention, through farmers proactively managing heat stress as per the Australian Cool-Cows (www.coolcows.com.au/) guidelines. 


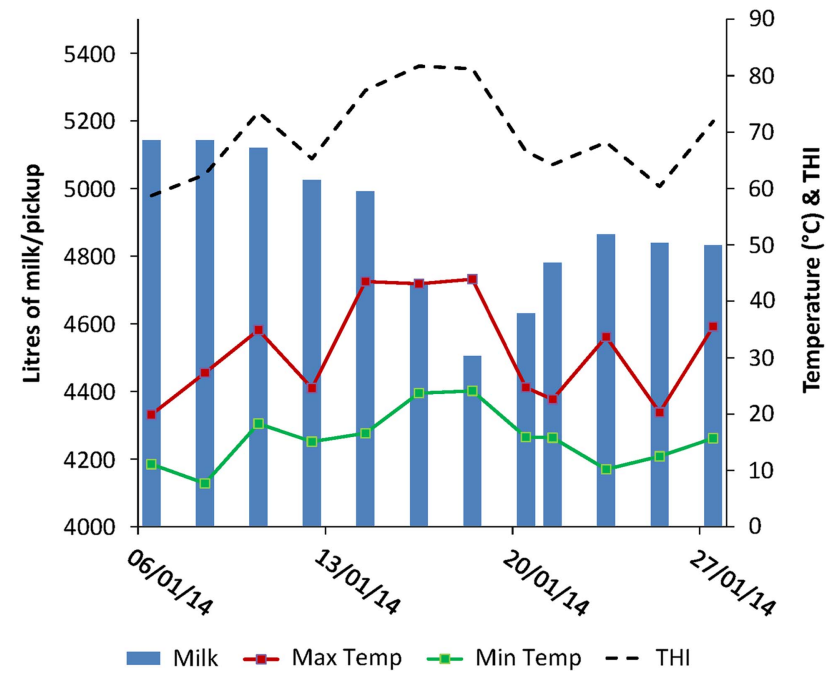

Figure 1 Daily milk tanker volumes (litres of milk/2-day pickup) from 640 dairy farms across the state of Victoria, Australia, shown with statewide average maximum and minimum temperatures and calculated Temperature Humidity Index (THI). Dairy breeds on these farms included Holstein-Friesian, Jersey and crosses.

\section{Adaptation options for sheep and goat farmers in Ethiopia} Developing countries are highly vulnerable to climate change since their economy predominantly relies on rain-fed agriculture where production is dependent on weather and other natural factors. In arid and semi-arid regions of Africa, livestock species, particularly sheep and goats are typically a major source of livelihood and survival. They are a source of food for rural people but, additionally, they may be converted to cash to meet household financial needs. In these traditional farming systems a low level of technology adoption increases vulnerability to impacts of climate change and limits options available to develop effective adaptation strategies.

Feleke et al. (2016) investigated choices being made by sheep and goat farmers in northern Ethiopia to adapt to changes in climate causing thermal, nutritional and water stresses. Of the farmers surveyed, almost $99 \%$ had noticed changes in climate with most respondents seeing a rise in temperature and a marked decline in rainfall. Farmers were implementing multiple adaptation responses (Table 2) depending on their circumstances and resources. During extreme events such as long dry periods when feed and water were deficient, the most common strategy was marketing. Despite poor prices, over $96 \%$ of farmers surveyed chose to sell their sheep and goats due to poor natural grazing and feed shortages. Home feeding was practised by about $90 \%$ of farmers. Practices more common in developed countries during temperature extremes such as provision of shelter or outside shade trees were less used in Ethiopia. Costs and forward planning for establishing trees in previously cleared grasslands and costs related to building housing and providing bedding will likely remain a barrier into the future. In the case of goat farmers, low shade provision may also be related to the relative heat tolerance of these animals.
Table 2 Adaptation options used by sheep and goat farmers surveyed by Feleke et al. (2016)

\begin{tabular}{lcccc}
\hline \hline & \multicolumn{2}{l}{$\begin{array}{l}\text { \% respondents per agro-ecological } \\
\text { region of northern Ethiopia }\end{array}$} & \\
\cline { 2 - 4 } Adaptation option & Lowland & Midland & Highland & Total \\
\hline Shade provision & 23 & 54 & 53 & 41 \\
Home feeding & 87 & 97 & 89 & 90 \\
Use of crossbred animals & 53 & 48 & 62 & 54 \\
Marketing (during extremes) & 99 & 95 & 97 & 96 \\
\hline
\end{tabular}

${ }^{1}$ Percentages are rounded

Analysis showed that access to information, farming experience, number of households in a village, distance to main market, income and agro-ecological settings influenced farmers' adaptation choices to climate change. Where adaptation strategies were implemented there was a positive influence on the household income. More effective options such as using crossbred animals were correlated with higher income. Feleke et al. (2016) propose the development of education and early climate warning systems for local farmers in regions such as northern Ethiopia, but note that support would still be needed to enable adoption of proactive adaptation approaches suited to different agro-climatic conditions. For example, government policy positions and initial support for low-technology regional programs such as planting shade trees and drought-tolerant browse species in grasslands may help to build climate resilience at relatively low cost.

\section{Future prospects, knowledge gaps and research approaches}

Ruminant production systems will need to adapt as the climate continues to change, and do so against a background expectation that they will also contribute to greenhouse gas reduction targets and to minimising other negative environmental impacts. Projected increases in extreme weather events and changes in feed availability, composition and quality, and animal diets will affect availability of animal products and food supply. These effects are likely to be greatest in developing countries where population and demand for food is greatest. Some of the negative consequences of climate change for ruminant livestock production can be mitigated through use of adaptive management and breeding approaches. Examples include use of energyefficient cooling systems for animals, proper nutrition and water access, use of more heat tolerant breeds, and genetic selection to improve fertility and survival under heat stress conditions. Improvements through use of diet and management are relatively immediate as documented by improving, though limited, resilience to recent climate extremes due to adaptive management practices by some livestock producers. However, improvements through genetic selection are slow and, therefore, development of long-term strategies to mitigate the effects of climate variation should not be delayed. 
More research is needed to understand the forage species mix and water security options most likely to support livestock ranging from high performing dairy cattle to hardy beef cattle, sheep and goats. While studies on the effects of heat stress in animals have revealed important physiological responses, most of the studies have been short term. There is a lack of knowledge on the effects of extended exposure to heat stress and its cumulative effect under farm conditions. Furthermore, research is needed to understand the potential rate of natural selection between forage species and whether this can keep pace with the rate of climate change - particularly separating native rangeland species with a broader genetic base, from highly bred and selected forage species. Research on impacts needs to include placing an economic cost on extreme climate events, as well as costing the proactive response options. This will allow farmers to make more informed choices on likely payback periods for investment in adaptation and help prioritise research investment by industry and governments.

Further research is needed on the likely tipping points of forage species by location, under a changing climate. This information is required by researchers seeking alternative forage species, as well as by farmers and consultants in knowing when to establish alternative forages. This type of analysis should include both annual (where regular reestablishment of forages may be an option) and multi-decadal evaluation of the sustainability of comparative systems. In addition, further research is needed to determine which pests and diseases of consequence are likely to move into new regions due to climate change.

\section{Acknowledgements}

The authors thank the organising committee of the International Symposium on the Nutrition of Herbivores (ISNH) for their invitation and encouragement to prepare this review. The authors also thank the anonymous reviewers whose critiques and comments greatly improved the manuscript.

\section{Declaration of interest}

The authors declare no conflict of interest.

\section{Ethics statement}

Conducting this review involved no animal handling or procedures.

\section{Software and data repository resources}

No new software or original data resources were generated as part of this study.

\section{References}

Australian Bureau of Meteorology 2014. Special Climate Statement 48 - one of southeast Australia's most significant heatwaves, Updated 21 August 2014. Publishing Unit, Bureau of Meteorology, Melbourne. Retrieved on 27 October 2017, from http://www.bom.gov.au/climate/current/statements/scs48.pdf.

Burrows WH, Henry BK, Back PV, Hoffman MB, Tait LJ, Anderson ER, Menke N, Danaher T, Carter JO and McKeon GM 2002. Growth and carbon stock change in eucalypt woodlands in north-east Australia: ecological and greenhouse sink implications. Global Change Biology 8, 769-784.

Craine JM, Angerer JP, Elmore A and Fierer N 2016. Continental-scale patterns reveal potential for warming-induced shifts in cattle diet. PLoS ONE 11, e0161511.

Craine JM, Elmore AJ and Angerer JP 2017. Long-term declines in dietary nutritional quality for North American cattle. Environmental Research Letters 12, 044019.

Craine JM, Ocheltree TW, Nippert JB, Towne EG, Skibbe AM, Kembel SW and Fargione JE 2013. Global diversity of drought tolerance and grassland climatechange resilience. Nature Climate Change 3, 63-67.

Cullen BR, Eckard RJ and Rawnsley RP 2012. Resistance of pasture production to projected climate changes in south-eastern Australia. Crop and Pasture Science 63, 77-86.

Das R, Sailo L, Verma N, Bharti P, Saikia J, Imtiwati, and Kumar R 2016. Impact of heat stress on health and performance of dairy animals: a review. Veterinary World 9, 260-268.

Davis SR, Spelman RJ and Littlejohn MD 2017. Breeding and genetics symposium: breeding heat tolerant dairy cattle: the case for introgression of the "slick" prolactin receptor variant into Bos taurus dairy breeds. Journal of Animal Science $95,1788-1800$

Dikmen S, Cole JB, Null DJ and Hansen PJ 2012. Heritability of rectal temperature and genetic correlations with production and reproduction traits in dairy cattle. Journal of Dairy Science 95, 3401-3405.

Dumont B, Andueza D, Niderkorn V, Lüscher A, Porqueddu C and Picon-Cochard C 2015. A meta-analysis of climate change effects on forage quality in grasslands: specificities of mountain and Mediterranean areas. Grass and Forage Science 70, 239-254.

Dunshea FR, Leury BJ, Fahri F, DiGiacomo K, Hung A, Chauhan S and Gaughan JB 2013. Amelioration of thermal stress impacts in dairy cows. Animal Production Science 53, 965-975.

Eisler MC, Lee MR, Tarlton JF, Martin GB, Beddington J, Dungait JA, Greathead H, Liu J, Mathew S, Miller H and Misselbrook T 2014. Agriculture: steps to sustainable livestock. Nature 507, 32-34.

Feleke FB, Berhe M, Gebru G and Hoag D 2016. Determinants of adaptation choices to climate change by sheep and goat farmers in Northern Ethiopia: the case of Southern and Central Tigray, Ethiopia. SpringerPlus 5, 1692.

Gantner V, Bobic T, Gantner R, Gregic M, Kuterovac K, Novakovic J and Potocnik K 2017. Differences in response to heat stress due to production level and breed of dairy cows. International Journal of Biometeorology 61, 1675-1685.

Garner JB, Douglas M, Williams SRO, Wales WJ, Marett LC, DiGiacomo K, Leury BJ and Hayes BJ 2017. Responses of dairy cows to short-term heat stress in controlled-climate chambers. Animal Production Science 57, 1233-1241.

Gaughan J 2017. Projected impacts of climate changes and sustainability of sheep production systems. In Sheep production adapting to climate change (ed. V Sejian, R Bhatta, J Gaughan, PK Malik, SMK Naqvi and R Lal), pp. 189-196. Springer, Singapore.

Gaughan J, Lacetera N, Valtorta SE, Khalifa HH, Hahn L and Mader T 2009. Response of domestic animals to climate challenges. In Biometeorology for adaptation to climate variability and change (ed. KL Ebi, I Burton and GR McGregor), pp. 131-170. Springer, Dordrecht, The Netherlands.

Gaughan JB, Bonner S, Loxton I, Mader TL, Lisle A and Lawrence R 2010a. Effect of shade on body temperature and performance of feedlot steers. Journal of Animal Science 88, 4056-4067.

Gaughan JB, Mader TL, Holt SM, Sullivan ML and Hahn GL 2010b. Assessing the heat tolerance of 17 beef cattle genotypes. International Journal of Biometeorology 54, 617-627.

Gauly M, Bollwein H, Breves G, Brügemann K, Dänicke S, Daș G, Demeler J, Hansen H, Isselstein J, König S and Lohölter M 2013. Future consequences and challenges for dairy cow production systems arising from climate change in Central Europe - a review. Animal 7, 843-859.

Ghesquière $M$, Humphreys MW and Zwierzykowski Z 2010. Festulolium. In Fodder crops and amenity grasses (ed. B Boller, UK Posselt and F Veronesi), pp. 288-311. Springer, New York, NY, USA.

Hansen PJ 2004. Physiological and cellular adaptations of zebu cattle to thermal stress. Animal Reproduction Science 82, 349-360.

Harle KJ, Howden SM, Hunt LP and Dunlop M 2007. The potential impact of climate change on the Australian wool industry by 2030. Agricultural Systems $93,61-89$. 
Henry, Eckard and Beauchemin

Hayes BJ, Lewin HA and Goddard ME 2013. The future of livestock breeding: genomic selection for efficiency, reduced emissions intensity, and adaptation. Trends in Genetics 29, 206-214.

Hennessy KJ, Whetton PH and Preston B 2010. Climate projections. In Adapting agriculture to climate change (ed. CJ Stokes and SM Howden), pp. 13-20. CSIRO Publishing Collingwood, Victoria, Australia.

Henry B, Charmley E, Eckard R, Gaughan JB and Hegarty R 2012. Livestock production in a changing climate: adaptation and mitigation research in Australia. Crop and Pasture Science 63, 191-202.

Higgins SF, Agouridis CT and Gumbert AA 2008. Drinking water quality guidelines for cattle. University of Kentucky Extension Service. Retrieved on 29 November 2017, from http://www2.ca.uky.edu/agc/pubs/id/id170/id170.pdf.

Hoekstra NJ, Suter M, Finn JA, Husse S and Lüscher A 2015. Do belowground vertical niche differences between deep and shallow-rooted species enhance resource uptake and drought resistance in grassland mixtures? Plant Soil 394, 21-34.

Hoffmann AA and Sgrò CM 2011. Climate change and evolutionary adaptation. Nature 470, 479-485.

Howden SM, Crimp SJ and Stokes CJ 2008. Climate change and Australian livestock systems: impacts, research and policy issues. Australian Journal of Experimental Agriculture 48, 780-788.

Kadzere CT, Murphy MR, Silanikove N and Maltz E 2002. Heat stress in lactating dairy cows: a review. Livestock Production Science 77, 59-91.

Kaliber M, Koluman N and Silanikove N 2016. Physiological and behavioral basis for the successful adaptation of goats to severe water restriction under hot environmental conditions. Animal 10, 82-88.

Key $\mathrm{N}$ and Sneeringer S 2014. Potential effects of climate change on the productivity of U.S. dairies. American Journal of Agricultural Economics 96, 1136-1156.

King AD and Karoly DJ 2017. Climate extremes in Europe at 1.5 and 2 degrees of global warming. Environmental Research Letters 12, 114031.

King AD, Karoly DJ and Henley BJ 2017. Australian climate extremes at 1.5 and 2 degrees of global warming. Nature Climate Change 7, 412-416.

Kovats RS, Campbell-Lendrum DH, McMichael AJ, Woodward A and Cox JSH 2001. Early effects of climate change: do they include changes in vector-borne disease? Philosophical Transactions of the Royal Society, London, Series B 356, 1058-1068.

Liu X, Zhang B, Henry B, Zhang J and Grace P 2017. Assessing the impact of historical and future climate change on Australian potential natural vegetation types and NPP in Australian grazing lands. The Rangeland Journal 39, 387-400.

Mader TL, Davis MS and Brown-Brandl T 2006. Environmental factors influencing heat stress in feedlot cattle. Journal of Animal Science 84, 712-719.

McCrabb GJ, McDonald BJ and Hennoste LM 1993. Heat stress during midpregnancy in sheep and the consequences for placental and fetal growth. The Journal of Agricultural Science 120, 265-271.

McKeon GM, Stone GS, Syktus Jl, Carter J0, Flood NR, Ahrens DG, Bruget DN Chilcott CR, Cobon DH, Cowley RA and Crimp SJ 2009. Climate change impacts on northern Australian rangeland livestock carrying capacity: a review of issues. The Rangeland Journal 31, 1-29.

Misztal I 2017. Breeding and genetics symposium: resilience and lessons from studies in genetics of heat stress. Journal of Animal Science 95, 1780-1787.

Morignat E, Perrin JB, Gay E, Vinard JL, Calavas D and Henaux V 2014. Assessment of the impact of the 2003 and 2006 heat waves on cattle mortality in France. PLoS ONE 9, e93176.

Mottet A, de Haan C, Falcucci A, Tempio G, Opio C and Gerber P 2017. Livestock: on our plates or eating at our table? A new analysis of the feed/ food debate. Global Food Security 14, 1-8.

National Oceanic and Atmospheric Administration (NOAA) National Centers for Environmental Information, State of the Climate: Global Climate Report for Annual 2016. Retrieved on 27 November 2017 from https://www.ncdc.noaa. gov/sotc/global/201613.

Nidumolu U, Crimp S, Gobbett D, Laing A, Howden M and Little S 2010. Heat stress in dairy cattle in northern Victoria: responses to a changing climate. CSIRO Climate Adaptation Flagship Working Paper No. 10. Retrieved on 24 November 2017, from http://research.csiro.au/climate/wp-content/uploads/.
Olson TA, Lucena C, Chase CC and Hammond AC 2003. Evidence of a major gene influencing hair length and heat tolerance in cattle. Journal of Animal Science 81, 80-90.

Opio C, Gerber P and Steinfeld H 2011. Livestock and the environment: addressing the consequences of livestock sector growth. Advances in Animal Biosciences 2, 601-607.

Renaudeau D, Collin A, Yahav S, De Basilio V, Gourdine JL and Collier RJ 2012. Adaptation to hot climate and strategies to alleviate heat stress in livestock production. Animal 6, 707-728.

Scheiter S and Higgins SI 2009. Impacts of climate change on the vegetation of Africa: an adaptive dynamic vegetation modelling approach. Global Change Biology 15, 2224-2246.

Sejian V, Kumar D, Gaughan JB and Naqvi SM 2017. Effect of multiple environmental stressors on the adaptive capability of Malpura rams based on physiological responses in a semi-arid tropical environment. Journal of Veterinary Behavior: Clinical Applications and Research 17, 6-13.

Seo SN and Mendelsohn R 2008. Measuring impacts and adaptations to climate change: a structural Ricardian model of African livestock management. Agricultural Economics 38, 151-165.

Seo SN, McCarl BA and Mendelsohn R 2010. From beef cattle to sheep under global warming? An analysis of adaptation by livestock species choice in South America. Ecological Economics 69, 2486-2494.

Silanikove N 2000. The physiological basis of adaptation in goats to harsh environments. Small Ruminant Research 35, 181-193.

Silanikove N, Shapiro F and Shinder D 2009. Acute heat stress brings down milk secretion in dairy cows by up-regulating the activity of the milk-borne negative feedback regulatory system. BMC Physiology 9, 13-13.

Snyman HA, Ingram LJ and Kirkman KP 2013. Themeda triandra: a keystone grass species. African Journal of Range \& Forage Science 30, 99-125.

Stagge JH, Kingston DG, Tallaksen LM and Hannah DM 2017. Observed drought indices show increasing divergence across Europe. Scientific Reports 7 , 14045.

Tebaldi C and Wehner MF 2018. Benefits of mitigation for future heat extremes under RCP4.5 compared to RCP8.5. Climatic Change 146, 349-361.

Thirumalai K, DiNezio PN, Okumura Y and Deser C 2017. Extreme temperatures in Southeast Asia caused by El Nino and worsened by global warming. Nature Communications 8, 15531.

Thornton PK, van de Steeg J, Notenbaert A and Herrero M 2009. The impacts of climate change on livestock and livestock systems in developing countries: a review of what we know and what we need to know. Agricultural Systems 101, 113-127.

United Nations Framework Convention on Climate Change (UNFCCC) 2015 Adoption of the Paris Agreement, Conference of the Parties, Paris, France, 30 November to 11 December, 2015. FCCC/CP/2015/L.9/Rev.1 Retrieved on 24 November 2017, from http://unfccc.int/documentation/documents/advanced search/items/6911.php?priref=600008831.

Usman T, Qureshi MS, Yu Y and Wang Y 2013. Influence of various environmental factors on dairy production and adaptability of Holstein cattle maintained under tropical and subtropical conditions. Advances in Environmental Biology 7, 366-372.

Wilkinson JM and Lee MRF 2017. Use of human-edible animal feeds by ruminant livestock. Animal, 1-9. https://doi.org/10.1017/S175173111700218X Published online: 12 September 2017.

Wright EC, Boehmer BH, Cooper-Prado MJ, Bailey CL and Wettemann RP 2014. Effect of elevated ambient temperature at parturition on duration of gestation, ruminal temperature, and endocrine function of fall-calving beef cows. Journal of Animal Science 92, 4449-4456.

Zhu Z, Piao S, Myneni RB, Huang M, Zeng Z, Canadell JG, Ciais P, Sitch S, Friedlingstein P, Arneth A, Cao C, Cheng L, Kato E, Koven C, Li Y, Lian X, Liu Y, Liu R, Mao J, Pan Y, Peng S, Peñuelas J, Poulter B, Pugh TAM, Stocker BD, Viovy N, Wang $X$, Wang Y, Xiao Z, Yang H, Zaehle S and Zeng N 2016. Greening of the Earth and its drivers. Nature Climate Change 6, 791-795. 